\title{
PATRIA Y DERECHOS. CONFIGURACIONES DISCURSIVAS EN LOS DISCURSOS PREVIOS AL BALOTAJE DE LA PRESIDENTA CRISTINA FERNÁNDEZ EN LA ARGENTINA
}

\author{
HOMELAND AND RIGHTS. DISCURSIVE CONFIGURATIONS \\ IN THE SPEECHES BEFORE THE BALOTAJE \\ OF THE PRESIDENT CRISTINA FERNÁNDEZ IN ARGENTINA
}

\section{RESUMEN}

A partir de las categorías proporcionadas por el modelo analítico de Eliseo Verón, el presente trabajo pretende analizar los discursos pronunciados por la Presidenta de Argentina, Cristina Fernández, durante el período comprendido entre las semanas anteriores a la realización del balotaje presidencial de 2015 hasta la finalización del mandato presidencial, el 10 de diciembre del mismo año. Pretendemos indagar en las próximas páginas en el modo en que dichos discursos exhiben las huellas de producción del universo discursivo kirchnerista y peronista, lo que se traduce en la presencia de entidades y metacolectivos que remiten al registro de ambas tradiciones políticas. A su vez, indagamos en los modos en que dichas formaciones discursivas articulan el "paradigma discursivo de los derechos" con el "modelo de la Patria", variando de acuerdo a los diferentes destinatarios a quienes estuvieron dirigidos.

Palabras clave: derechos; destinatarios; discurso; patria; pueblo.

\begin{abstract}
Based on the categories provided by Eliseo Verón's analytical model, this paper aims to analyze the speeches made by the former President of Argentina, Cristina Fernández, during the period between the weeks prior to the 2015 presidential balloting finalization of the presidential mandate, on december 10 of the same year. Fundamentally, in the following pages we intend to investigate the way in which these discourses exhibit the traces of production of the Kirchnerist and Peronist discursive universe, which translates into the presence of entities and metacolectives that refer to the register of both political traditions. At the same time, we investigate the ways in which these discursive formations articulate the "discursive paradigm of rights" with the "model of the Fatherland", varying according to the different recipients and audiences to whom they are directed.
\end{abstract}

Keywords: homeland; receiver; rights; speech; town. 


\section{INTRODUCCIÓN}

El Análisis del Discurso se inscribe en una larga tradición teórica que, al decir de Ana Montero, desde los años sesenta se ha ocupado de vincular la lingüística con la historia, la ideología y lo político (Montero 2012:26). En Argentina, dichos postulados fueron recuperados en las investigaciones de autores tales como Eliseo Verón, cuyas características fundamentales radican, siguiendo a Fabiana Martínez (s.f.), en la puesta en cuestión de las relaciones de determinación clásica en la circulación discursiva; la desreificación de categorías tales como ideología y poder, el predominio del análisis de diversas materialidades significantes y la evidente presencia de categorías vinculadas a la enunciación.

A partir de la propuesta analítica de Verón, el presente trabajo pretende analizar los discursos pronunciados por la Presidenta de la Argentina, Cristina Fernández, durante el período comprendido entre las semanas previas a la realización del ballotaje presidencial de 2015 hasta la finalización de su mandato, el 10 de diciembre del mismo año.

Dichos discursos, fueron pronunciados en un contexto histórico muy singular, puesto que se inscribieron en el marco de la posible derrota electoral, en las elecciones presidenciales, del Frente Para La Victoria (fuerza política liderada por la entonces Presidenta Cristina Fernández, e integrada por diversos partidos tales como el Nuevo Encuentro, Partido Solidario, Partido Humanista, Partido Intransigente, Frente Grande, un sector del Partido Justicialista y de la Unión Cívica Radical, entre otros) frente a la Alianza Cambiemos (conformada por Propuesta Republicana/PRO, un sector del radicalismo y la Coalición Cívica) posibilidad que se concretó en el ballotaje del 22 de noviembre de 2015. Desde la asunción de Néstor Kirchner en el año 2003 el Frente Para La Victoria había obtenido el voto mayoritario de la ciudadanía en las elecciones presidenciales posteriores, consagrando a Cristina Fernández como Presidenta de la Nación en el año 2007, quién resultó reelecta en los comicios de 2011 con el 53 por ciento de los votos.

El ballotaje, o segunda vuelta, fue incorporado a la Constitución Nacional Argentina a partir de la reforma constitucional de 1994 como mecanismo obligatorio para aquellos casos en que, en el marco de elecciones presidenciales, el candidato con mayor porcentaje de votos no obtuviera más del 45 por ciento de los votos afirmativos válidamente emitidos o, que habiendo obtenido más del 40 por ciento no exista una diferencia de diez puntos porcentuales en relación a la segunda fuerza más votada (Constitución de la Nación Argentina, arts. 97 y 98).

El escenario político en el que la Presidenta pronunció los discursos analizados es particular, entonces, tanto por la circunstancia que implicaba una posible derrota electoral en comicios presidenciales por parte del Frente Para la Victoria en el contexto del ballotaje; sino también, por tratarse de la primera oportunidad en la que se realizó la segunda vuelta electoral en la República Argentina, figura que desde su incorporación a la Carta Magna Argentina no se había implementado.

Considerando la singularidad del contexto político en el que se inscriben los discursos que serán objeto de análisis en las próximas páginas, recuperamos en los párrafos siguientes aportes de diferentes autores que analizan el fenómeno kirchnerista desde la ciencia política y el análisis del discurso.

Susana Bonetto (2015) ha postulado que lo que se denomina "la década kirchnerista" estuvo signada por una serie de transformaciones que, fundamentalmente, radican en la reformulación de la política como escenario legítimo de representación y transformación de la sociedad, la construcción de una alternativa viable al neoliberalismo y el sostenimiento de una propuesta de ampliación de derechos y de equidad social. 
De este modo, siguiendo a la autora, los doce años de kirchnerismo se inscriben en un período conceptualizado como el de la Argentina "post neoliberal", que implicó una revalorización del poder de decisión política por sobre la sujeción a la ortodoxia económica propia del neoliberalismo, y por la emergencia de una gran cantidad de colectivos sociales, entre los que se destacan la movilización militante y las organizaciones políticas de la juventud (Bonetto 2015).

En una línea de análisis similar, y destacando el punto de escisión entre el kirchnerismo y las experiencias de gobierno anteriores, Fabiana Martínez (2015) afirma que el discurso kirchnerista inauguró en la Argentina una hegemonía fuertemente diferenciada de aquella imperante en el país durante los años noventa. Se configuró, así, una matriz discursiva que recuperó la concepción de lo político como orden legítimo de regulación de lo social; reemplazando las formulaciones que encontraban como fundamento único de la decisión política a la lógica de mercado.

Asimismo, en tales discursos asumieron un protagonismo relevante las demandas excluidas en la década anterior, a la vez que se configuró un "enunciador postmenemista" (Martínez 2010:5) mediante operaciones de inversión de los tópicos neoliberales que terminaron invistiendo a la esfera política de sentidos completamente diferentes, a partir de la construcción de parejas axiológicas (Estado/mercado; memoria/olvido, por ejemplo). La hegemonía propuesta por el kirchnerista se caracterizó por la valoración de las instancias de lo público y lo colectivo y la reconfiguración de la figura del Estado como una institución con capacidad para intervenir en el ordenamiento social.

Al tensionar el paradigma neoliberal que concebía al orden social como orden regulado por el mercado, la definición del proyecto político kirchnerista como propuesta que afectó a grupos concentrados de la economía $\mathrm{y}$ beneficiados por las políticas económicas del gobierno menemista, imprimió una discursividad adversativa al discurso kirchnerista (Martínez 2015). Afirmando que el kirchnerismo ha presentado como valores fundamentales a la distribución de la riqueza y la inclusión, Martínez indica que dicha discursividad se ve atravesada por un principio estructurante antagonista, en donde destacan las concepciones de "democracia como litigio y política como conflicto" (Martínez 2015).

Por otra parte, Martín Retamozo ha analizado la presencia de la discursividad peronista en los gobiernos kirchneristas.
El autor postula que el kirchneris- mo reactivó una lectura del peronis- mo como experiencia, recuperando “...la matriz plebeya, subalterniza- da como identidad en la estructura del Partido Justicialista y sonám- bula en experiencias sindicales $\mathrm{y}$ de movimientos sociales [que] reapareció con una capacidad de interpelación que no estaba en los papeles..." (Retamozo 2015:15).

En el plano simbólico, señala el mencionado autor que el kirchnerismo ha logrado, mediante la reactivación de una lectura particular del peronismo, comenzar a producir sus propios mitos. En este contexto, destaca como notas distintivas de la discursividad kirchnerista la recuperación de la tradición "nacional y popular", con sus referencias al Estado como "redentor" (Retamozo 2015:17) y la fuerte presencia del sujeto "pueblo".

El ethos construido por los discursos de las figuras más fuertes del kirchnerismo ha constituido, también, el objeto de estudio de numerosos trabajos e investigaciones científicas. Dentro de este grupo, destacamos las propuestas de Ana Montero (2012), quien realiza un análisis del discurso kirchnerista en referencia a la memoria del pasado reciente y la revalorización de los derechos humanos, postulando que uno de los rasgos distintivos de dicho discurso reside en haber recuperado un imaginario político nunca antes reivindicado desde la posición de enunciación presidencial: el imaginario configurado en torno a 
la "memoria militante setentista" que remite a los jóvenes militantes de los años setenta con sus modos de imaginar y representarse la política (Montero 2012:16-17).

De este modo, la autora postula que el discurso kirchnerista evoca y reelabora elementos de la "memoria militante setentista" lo que contribuyó a la configuración de un ethos presidencial, proyectado como ethos militante.

\begin{abstract}
Así, encontramos que “...el setentismo (...) funciona como una memoria discursiva inscripta en el propio ethos presidencial..." (Montero 2012:20), que se manifiesta en la evocación de discursos, tonos, puntos de vista, que instauran umbrales de lo decible.
\end{abstract}

Recuperando los aportes desarrollados, sostenemos que los discursos de Cristina Fernández en el contexto particular que significaron las semanas previas al ballotaje y al cumplimiento del mandato presidencial, exhiben las huellas de producción del universo discursivo kirchnerista y peronista, lo que se traduce en la presencia de entidades y metacolectivos (Sigal y Verón 2003) que remiten al registro de ambas tradiciones políticas.

Así, se conjuga la alusión a metacolectivos tales como "pueblo", característico de la enunciación peronista (Retamozo 2015) y el énfasis en la figura del adversario o contradestinatario, a la vez que se recuperan las concepciones de "democracia como litigio y política como conflicto", propias del universo discursivo kirchnerista (Martínez 2010).

Por último, en los discursos de la Presidenta se combina el "ethos militante" (Montero 2012) con la imagen de mujer peronista que realza la enunciadora (Vitale 2013). Como resultado de esta yuxtaposición, los discursos de Cristina Fernández proyectan un ethos configurado por su condición de mujer militante de una fuerza política inscripta en la tradición nacional-popular desde un "modelo de llegada" (Sigal y Verón 2003) que enfatiza la trayectoria política de la enunciadora.

\section{METODOLOGÍA}

La metodología empleada para la realización de la presente investigación fue de carácter eminentemente cualitativo, e incluyó dos etapas. La primera, heurística, que consistió en la búsqueda y selección de los diferentes discursos pronunciados por la ex mandataria en la Argentina en el período comprendido entre los días previos a la realización de la segunda vuelta electoral y la finalización del mandato presidencial. En este aspecto, cabe destacar que la totalidad de los discursos seleccionados y sometidos a posterior análisis fueron extraídos de la página web oficial de Cristina Fernández www.cfkargentina.com

La segunda, de carácter hermenéutico, consistente en el análisis detallado, a partir de las herramientas y categorías teóricas que aporta Eliseo Verón, de las enunciaciones discursivas analizadas, como así también la posterior sistematización de las conclusiones arribadas en un informe escrito y que constituye el cuerpo del presente trabajo.

\section{RESULTADOS Y DISCUSIÓN}

\section{La condición adversativa en los discur- sos de Cristina Fernández: destinatarios múltiples en el escenario pre ballotaje}

Eliseo Verón postula que el campo discursivo de lo político implica enfrentamiento, relación con un enemigo, por lo que este tipo de discurso asume como nota característica el ser un "discurso polémico" (Verón 1987:15). Desde esta perspectiva, todo acto de enunciación política está habitado por un "otro negativo" (Verón 1987), a la vez que construye un otro positivo, operando de esta manera un desdoblamiento en la destinación (Verón 1987:16). 
Siguiendo a Arfuch (1987), la interpelación juega un papel importante en la constitución del destinatario, ya que ofrece una imagen donde puede reconocerse un colectivo de identificación o prodestinatario. Sin embargo, el discurso político incluye también al indeciso (paradestinatario, en los términos de Verón), como al adversario (contradestinatario). Para la autora citada, el discurso político y sobre todo el electoral, presenta una gran dificultad de acceso al "nosotros" inclusivo, en razón de la marcada diferenciación de roles entre el enunciador y los destinatarios (Arfuch 1987:35).

Si bien los discursos de Cristina Fernández en el marco de la campaña electoral previa al ballotaje, como los pronunciados en las semanas anteriores a la culminación de su mandato, se dirigen a los tres tipos de destinatarios caracterizados por Verón, se destaca la fuerte presencia del contradestinatario en tales formulaciones, condición que reafirma la "dimensión adversativa" (Martínez 2015) del discurso kirchnerista y su carácter eminentemente polémico, a la vez que exhorta a sus prodestinatarios, y paradestinatarios desde el empleo de fórmulas asociadas a componentes didácticos-prescriptivos, recuperando el "modelo de la patria" (Martínez 2010) e inscribiendo las políticas sostenidas por el kirchnerismo en el marco del "paradigma discursivo de los derechos" (Martínez 2013), interpelando desde tales formulaciones, tanto a paradestinatarios como a prodestinatarios, respectivamente.

El carácter polémico y adversativo en los discursos de Cristina Fernández se expresa en las frecuentes alusiones que formula en relación al "otro negativo", al adversario político. Así, la Presidenta dio apertura al discurso del nueve de diciembre de 2015, horas antes del cumplimiento de su mandato, mediante una clara referencia al contradestinatario:

Quiero decirles a todas y todos que si después de estos intensos doce años y medio, con todos los me- dios de comunicación hegemónicos en contra y después de estos doce años y medios con las principales corporaciones económicas y financieras nacionales e internacionales en contra, si después de doce años y medio de persecuciones y hostigamientos permanentes de lo que yo denomino el partido judicial, si después de todo eso, de tantos palos en la rueda, de tantos golpes e intentos de golpes destituyentes, después de tantos ataques, persecuciones, difamaciones y calumnias podemos estar aquí, dando cuentas al pueblo, imagino que si con tantas cosas en contra hemos hecho tantas cosas por los argentinos, cuantas podrán hacer los que tienen todos estos factores a favor. (Fernández 2015c)

De esta manera, caracteriza a su adversario no en referencia exclusiva al espacio político que resultó electo en el ballotaje sino que, fundamentalmente, vincula a la Alianza Cambiemos (sin nombrarla expresamente) a las corporaciones económicas, comunicacionales e institucionales.

La "sobredimensión de la función adversativa" del discurso kirchnerista (Balsa 2013), presente en este discurso se inscribe, según Balsa, en una estrategia intrínseca a una lógica recuperadora de la "dimensión agonal de la política" (Mouffe 1999). Asimismo, la referencia al adversario opera como instrumento mediante el que se delimitan las fronteras respecto al colectivo de identificación que traza las fronteras entre "nosotros" y "ellos".

En el contexto singular en que se pronuncia este discurso, la Presidenta reformula, mediante una "inversión especular" (Martínez 2010), una pareja axiológica que aparece como estructurante de una línea divisoria entre dos identidades políticas adversas. Mediante la antinomia "corporaciones/pueblo" se configura la base de la oposición entre los colectivos identitarios "ellos/nosotros", respectivamente. 
La referencia a un contradestinatario encarnado en la Alianza Cambiemos y asociado a las corporaciones que se erigen en "enemigos del pueblo" (Martínez 2010), reaparece cuando Cristina Fernández afirma: "Tengamos la inteligencia de saber que seguramente van a poder hacer las cosas porque lo tienen todo a favor" (Fernández 2015c).

Se proyecta un claro "otro negativo" que "tiene a su favor" a aquellos grupos concentrados que, conforme surge del discurso de la Presidenta, constituyeron auténticos poderes fácticos en razón de haber concertado "intentos de golpes destituyentes" (Fernán$\operatorname{dez} 2015 \mathrm{c})$.

Un "otro negativo" que, tal como indica Verón, materializa una "lectura destructiva de lo que define la posición del enunciador" (Verón 1980:17). A su vez, mediante lo que en apariencia representa una expresión de anhelo, se instituye en ese otro la encarnación de la potencial pérdida de los "derechos obtenidos", posibilidad que se observa en la manifestación de Cristina Fernández al expresar: "Espero una Argentina sin censuras, espero una Argentina sin represión, espero una Argentina más libre que nunca" (Fernández 2015c).

En consonancia con ello, las operaciones discursivas analizadas, se enmarcan en el "paradigma discursivo de los derechos" (Martínez 2013). Así, desde este paradigma se activan una serie de narrativas que condensan algunas de las políticas más significativas sostenidas por los gobiernos kirchneristas a la vez que las inscribe en el lenguaje marco de los derechos. Como nota distintiva entre el "modelo de la patria" (Martínez 2010) y el "paradigma discursivo de los derechos" (Martínez 2015), corresponde señalar que mientras el primero retoma las antinomias propios de la enunciación peronista (pueblo/ antipueblo; patria/corporaciones), y establece una nítida frontera entre colectivos excluidos (marginados, clase media, militantes de base, etc) y sus adversarios (corporaciones económicas, militares, entidades rurales, oligarquía) (Martínez 2010), el segundo remite a aquellas formaciones discursivas que operan en el registro marco de los derechos en tanto conquistas sociales, instituyendo al Estado en garante de derechos y ubicando al ciudadano o a la persona como contraparte (Martínez 2013).

Sostenemos que los discursos analizados en el presente trabajo, aunque combinan el "modelo de la patria" con el "paradigma discursivo de los derechos", exhiben una utilización diferencial de tales formaciones, ya que el paradigma de los derechos constituye una matriz a la que se recurre fundamentalmente en aquellas operaciones que tienen como objeto interpelar al paradestinatario, y cumple dos funciones: por un lado, de reconstrucción histórica de la propia trayectoria de gobierno, puesto que permite enumerar las políticas de los gobiernos kirchneristas y, por otro, de advertencia sobre la el potencial avance de futuros gobiernos sobre tales conquistas lo que se traduciría, a su vez, en una pérdida de derechos de los ciudadanos.

Desde este lugar, Cristina Fernández interpela a la ciudadanía y la erige como guardián de sus propios derechos, estableciendo al "empoderamiento" (Fernández 2015c) como presupuesto de acción política. De este modo, en el último discurso pronunciado en calidad de Presidenta de la Nación, se dirige a múltiples entidades que integran la ciudadanía y, en lo que puede leerse como un acto de rendición de cuentas, donde la enunciadora afirma que puede "... mirar a los ojos..." a sus "compatriotas", en lo que podría constituir una referencia a una suerte de compromiso cumplido, señala:

Podemos mirar a los ojos de los trabajadores para decirles que nunca los traicionamos, para decirles que siempre tuvieron paritarias libres (...) podemos mirar a los ojos de los científicos, de los que volvieron $\mathrm{y}$ de los que se quedaron para hacer el aguante y decirles que les hemos reconocido sus derechos, sus saberes, sus conocimientos como nunca 
nadie lo había hecho (...) podemos mirar a los ojos de los docentes argentinos $(\ldots)$ y decirles que estamos destinando más del 6 por ciento del PBI para financiar la educación pública nacional y gratuita. Podemos mirar también a los ojos de los jóvenes universitarios, de los profesores universitarios (...) decir que jamás en las últimas décadas, no solo no se habían creado tantas universidades, sino que jamás las universidades argentinas contaron son los recursos para poder desarrollar infraestructura, salarios, investigaciones. (Fernández 2015c)

Se destacan entonces un conjunto de políticas que van desde Memoria, Verdad y Justicia hasta leyes tales como el matrimonio igualitario e identidad de género, que se reconstruyen a modo de constatación de la propia trayectoria de gobierno de la enunciadora y que son presentadas en la lengua de derechos:

No concebimos a los derechos humanos solamente como lo que ocurrió durante la dictadura, derechos humanos es lo de hoy (...) $Y$ quiero decirles que en nombre de esa libertad, no nos detuvimos en recuperar aquí el Sitio de la Memoria, que inauguramos hace poco tiempo; los edificios que inauguramos hoy. En estos años hemos recuperado la dignidad con el matrimonio igualitario, el derecho a la identidad de género. Eso es libertad, que nadie te diga a quién tenés que elegir amar. (Fernández 2015b)

En consonancia con el carácter fuertemente adversativo del discurso kirchnerista, en esta discursividad inscripta en el paradigma de derechos, la presencia del adversario asume una trascendencia fundamental en tanto permite sostener la propia identidad, a la vez que opera como mecanismo de persuasión al indeciso (Martínez 2010).

Así, la Presidenta destaca, en relación a las manifestaciones públicas formuladas por algunos miembros de la Alianza Cambiemos y cuyos representantes en el Congreso de la Nación votaron, en una gran mayoría, en contra de la ley de matrimonio igualitario sancionada en el año 2010: "La vida de cuánta gente no se habría solucionado, cuántos seguirían siendo infelices, cuántos seguirían a lo mejor encerrados en un closet porque la sociedad condenaba este tipo de cosas" (Fernández 2015a).

De este modo, la reconstrucción de las políticas desarrolladas durante el kirchnerismo se formula en el registro de la ampliación de derechos. La mandataria lo expresa claramente, mediante el empleo de un componente didáctico, correspondiente a la "modalidad del saber" (Verón 1980:21) dirigiéndose al paradestinatario en el siguiente fragmento:

\section{No hay programas sociales. La Asignación Universal por Hijo (...) no es un programa social, es un derecho que tienen aquellos o que no tienen trabajo o que tienen trabajo informal (...).De la misma manera que es un derecho la Asig- nación Familiar para el trabaja- dor registrado. (Fernández 2015a)}

En tales formaciones, la enunciadora explica, "enuncia un principio general" (Verón 1980:21) que le permite inscribir a la AUH (Asignación Universal por Hijo) en la lengua de derechos, a la vez que operar en el plano de la persuasión, nota distintiva de aquellos discursos que pretenden interpelar al paradestinatario, es decir, a aquellos "sectores de la ciudadanía que se encuentran, en cierto modo, 'fuera de juego' y que en los procesos electorales son identificados habitualmente como los indecisos" (Verón 1980:17).

La referencia a los derechos obtenidos por la ciudadanía argentina es un tópico de gran presencia en los discursos analizados. Recuperando esa dimensión, Cristina Fernández formula una advertencia sobre la posible pérdida de tales derechos y erige a la ciudadanía en guardián de los mismos. De este modo, se dirige al paradestinatario, y en el contexto del ballotaje, manifiesta: 
Que cada uno se plante en ese lugar y piense sinceramente y honestamente (...) quién es el que puede garantizar que esto siga para todos los argentinos (....) no defiendan a un gobierno, yo les pido que defiendan sus derechos, que cuando metan ese sobre en la urna, sepan que ahí dentro van sus derechos, todos sus derechos. (Fernández 2015a)

El empoderamiento aparece como una de los presupuestos necesarios para la acción y reflexión política que requiere la tarea ciudadana de "defender los derechos". En un discurso marcado por la dimensión adversativa y reivindicando la noción de política como conflicto, articulada al modelo de derechos, e interpelando al paradestinatario caracterizado como "ciudadano argentino", la Presidenta exhortó:

Cada uno de ustedes, cada uno de los 42 millones de argentinos, tiene un dirigente adentro y que cuando cada uno de ustedes, cada uno de esos 42 millones de argentinos sienta que aquellos en los que confió y depositó su voto, lo traicionaron, tome su bandera y sepa que él es el dirigente de su destino y el constructor de su vida, que esto es lo más grande que le he dado al pueblo argentino: el empoderamiento popular, el empoderamiento ciudadano, el empoderamiento de las libertades, el empoderamiento de los derechos. (Fernández 2015c)

En el fragmento arriba citado, es posible observar el modo en que se yuxtaponen y se superponen el modelo de la patria y el paradigma de los derechos, puesto que en la misma frase se condensan, por un lado, la referencia al "pueblo", metacolectivo del imaginario cuya presencia remite al modelo de la patria y al campo de formaciones discursivas del peronismo; mientras que por el otro, dirigiéndose al paradestinatario, presenta al "empoderamiento ciudadano" como presupuesto de acción política, interpelando directamente a "cada uno de los 42 millones de argentinos".
La afirmación de la política como conflicto se traduce en el mandato que sugiere que cada uno de los argentinos "tome su bandera" en el supuesto de verse "traicionado" por aquellos a quienes votó, lo que a su vez imprime a este discurso de un componente marcadamente prescriptivo. Sostenemos que en esta frase Cristina Fernández se dirige al paradestinatario, ya que de algún modo el prodestinatario, que comparte la "creencia presupuesta" con el enunciador, (Verón 1980:17), que representa a aquél receptor que "...participa de las mismas ideas y que adhiere a los mismos valores y persigue los mismos objetivos..." que quién enuncia el discurso (Verón 1980:17) es caracterizado en los discursos de Cristina Fernández como la "militancia", por lo que exhortar a los militantes a que "tomen sus banderas" y se sumen a la lucha política implicaría una redundancia en el discurso.

Sin embargo, este imperativo hace sentido cuando lo ubicamos en el marco de interpelación al paradestinatario; es decir, de aquél cuya posición respecto al enunciador del discurso implica una "hipótesis de suspensión de la creencia" (Verón 1980:17). Y, además, porque formula una suerte de advertencia a aquellos que se vean "traicionados" por las políticas desarrolladas por quienes votaron, operando de algún modo en el orden de la persuasión, lo que es característico de las operaciones discursivas dirigidas a los "indecisos" o paradestinatarios.

La referencia a una probable "traición" o "falta de honestidad" por parte de la fuerza política opositora es un tópico al que la mandataria alude con frecuencia al momento de caracterizar a su adversario y como operación de persuasión a los indecisos en el contexto del ballotaje. De este modo, afirma:

Yo creo en debates, creo además que los debates deberían ser acompañados además con versiones fílmicas de posiciones anteriores. Porque no sería honesto intelectualmente decir hoy que estamos de acuerdo con todo cuando hace apenas meses 
atrás, se estaba en desacuerdo con todo (...) Hoy nos dicen que no van a privatizar Aerolíneas Argentinas, pero están los documentos fílmicos de cuando decían que la iban a privatizar. (Fernández 2015a)

Tales formaciones varían en lo atinente al colectivo de identificación, que oscila entre el empleo de fórmulas que remiten a un nosotros inclusivo amplio, como las alusiones a "compatriotas y conciudadanos" (Fernández 2015c), afirmaciones que sostienen que: "Espero que podamos gozar, que todos los argentinos puedan gozar, de las conquistas sociales, del progreso económico" (Fernández 2015c) y tales como "...compatriotas, hemos hecho un acto de memoria, de verdad y de justicia..." (Fernández 2015b) mientras que, por otra parte, fórmulas de inclusión mucho más restrictivas, articuladas en torno a un "nosotros" que se configura alrededor exclusivamente del prodestinatario en tanto "partidario", son empleadas por la mandataria para conferir, a partir del componente prescriptivo del discurso, obligaciones y responsabilidades que el prodestinatario, en su condición de militante, debe ejercer. Estas características son observables en el siguiente fragmento:

Nosotros tenemos la responsabilidad de ser más maduros ¿Saben por qué? Porque nosotros amamos la Patria profundamente, nosotros creemos en el pueblo, creemos en lo que hemos hecho (...) nuestra responsabilidad es mucho más grande porque hemos construido esta Argentina de mayores derechos. (Fernández 2015c)

Compromiso político, amor por la patria y convicciones son los elementos mediante los que se articula la identidad política del "nosotros" restricitivo, lo que a su vez traza fronteras respecto al adversario político que, como hemos indicado anteriormente, forma parte de una cadena de intereses que involucra a las corporaciones y los poderes fácticos. Asimismo, el prodestinatario con- formado por este colectivo de identificación circunscrito, de algún modo, a la militancia, presenta en las formaciones discursivas analizadas atributos vinculados a una mayor competencia para interpretar la realidad argentina, lo que nuevamente marca una frontera de escisión entre ambos colectivos. Así, Cristina Fernández indica:

\begin{abstract}
¿Saben qué? (...) no necesitamos focus group. Nosotros tenemos una lectura de la realidad y, además, tenemos convicciones para transformar esa realidad que fue la que nos permitió darle a la Argentina el lapso de mayor estabilidad y gobernabilidad política, institucional, económica y social de la que se tenga memoria. (Fernández 2015b)
\end{abstract}

De este modo, en los discursos de la mandataria, prodestinatario y contradestinatario se configuran mediante operaciones que, recuperando elementos del universo discursivo peronista y kirchnerista, activan parejas axiológicas a partir de las que, tal como afirma Fabiana Martínez, se dicotomiza el campo social (Martínez 2010).

\section{Mujer militante: ethos y modelo de llega- da en los discursos de Cristina Fernández}

Los estudios sobre el ethos representan un campo de investigaciones de gran importancia en los trabajos que se inscriben en el análisis del discurso. Montero (2012) indica que la categoría ethos encuentra su origen en la retórica clásica aristotélica, como una de las tres formas de prueba para la persuasión.

Así, mientras el logos se asocia a la razón, el pathos y el ethos remiten a la disposición emotiva del auditorio y a la imagen o carácter del orador, respectivamente. Sin embargo, las teorías discursivas actuales presentan al ethos como la posición de subjetividad en una determinada discursividad.

De esta manera, señala la autora citada retomando a Maingueneau, el ethos funciona como el origen enunciativo, como la "...ins- 
tancia subjetiva encarnada en un cuerpo, una voz y un tono que permite dar cuenta de la identidad de los posicionamientos subjetivos" (Montero 2012:43).

El kirchnerismo ha sido caracterizado por su discursividad adversativa. Esta característica se relaciona con la configuración de un ethos particular que recupera la posición del enunciador como militante, operación mediante la que se construye liderazgo a partir del dominio en la actividad política (Martínez 2013).

Siguiendo a Montero, en la configuración del "ethos militante", el discurso kirchnerista recupera la "memoria militante setentista" que se sustenta en lo que la autora denomina un "espacio ideológico-argumentativo" (Montero 2012:64), caracterizado como una zona de intersección en el que acontecen relaciones de interdiscursividad entre un discurso de referencia y un cúmulo de discursos que remiten a un "espíritu de época". Desde ese espacio, se configura un marco discursivo que define los posicionamientos político-ideológicos del enunciador (Montero 2012).

Los discursos analizados de Cristina Fernández condensan en la configuración del ethos tanto la condición de militante, como la de mujer. La yuxtaposición de ambas posiciones de sujeto se expresa entonces en un ethos singular, que expresa una subjetividad determinada de la enunciadora en razón de su condición de mujer militante de una determinada tradición política de la Argentina. Así, la mandataria expresa: "Las mujeres del peronismo hemos hecho historia y vamos a seguir haciéndolo, planteando modelos de participación ciudadana, popular y democrática como nunca ningún otro partido o fuerza política lo ha hecho en la historia" (Fernández 2015a).

El campo discursivo en el que se inscribe el ethos de la enunciadora en este discurso no es el de las memorias militantes setentistas que caracterizó la discursividad de Néstor
Kirchner (Montero 2012) sino que, en el fragmento seleccionado, el ethos de quién enuncia se inscribe, fundamentalmente, en la genealogía del peronismo.

La adscripción a una fuerza política trascendente en la historia argentina y la alusión a la pertenencia al género femenino por parte de la enunciadora, constituyen operaciones que permiten a la locutora enmarcarse a sí misma en la historia de las mujeres del peronismo. Así, la Presidenta se presenta como eslabón de una cadena, de aquella construcción que históricamente significó "modelos de participación popular" en la Argentina y de la que ella representa un nuevo capítulo, una continuidad.

De este modo, evoca experiencias previas a la militancia setentista, recuperando e inscribiendo su propia trayectoria política en el marco de lo que fue la experiencia del primer peronismo en Argentina, lo que de alguna manera remite a la figura de Eva Duarte de Perón, como a la historia de resistencia encabezada por los trabajadores y sindicatos peronistas posterior al golpe de Estado de 1955.

Por otra parte, la adscripción al género femenino y las desigualdades estructurales que, por los propios imperativos de género, dificultan la participación de las mujeres en política en algunas ocasiones, es un elemento que asume gran relevancia en el ethos proyectado por Cristina Fernández, que destaca: "Porque una Presidenta (...) ha puesto la pica en Flandes para que las demás mujeres se animen a participar en el sistema de decisiones" (Fernández 2015a).

El ethos articulado en torno a la condición de mujer militante, asimismo, permite a la mandataria enmarcar la experiencia política propia en el derrotero de las luchas por las demandas de "juicio y castigo" por los delitos de lesa humanidad ejecutados durante el Terrorismo de Estado de la última dictadura cívico-militar-eclesiástica en la Argentina, a la vez que asumirse como parte de esas lu- 
chas. De este modo, señala: "Hace poco más de 11 años, en este lugar, no aquí adentro, todavía estábamos afuera en la calle pidiendo justicia, memoria y verdad" (Fernández 2015b).

Esa fuerza política a la que adscribe la enunciadora y que remite a una genealogía de luchas y demandas que se sostuvieron con la "presencia en las calles", se conjuga en una construcción mediante la que la Presidenta se asume como nuevo capítulo en la historia de las mujeres militantes del peronismo.

La proyección de este ethos asume gran protagonismo en la reivindicación de la "democracia como litigio" (Martínez 2010) ya que, desde su posición de militante de una fuerza política que remite a una historia de proscripciones y resistencias en Argentina, la mandataria desarrolla una estrategia discursiva que reafirma el lugar de la política como conflicto y de la democracia como litigio. Así, explica: "Ante la exhibición de las distintas boletas de distintos candidatos, que no son papeles, son propuestas de país, porque hay nombres e historias en cada uno de esos papeles" (Fernández 2015a).

La referencia a la presencia de diferentes "propuestas de país" en cada "boleta", enfatiza la dimensión agonal de la política y destaca la presencia de diferentes fuerzas que se disputan la construcción de la hegemonía (Mouffe 2000) en un orden democrático. Las notas características de discursividad adversativa del kirchnerismo se configuran en este contexto particular, reconociendo el componente litigioso de la democracia como la constante disputa y enfrentamiento entre fuerzas políticas opositoras con "propuestas de país" encontradas.

De esta manera, "la política aparece como un campo de lucha permanente más que un conjunto de relaciones complementarias en equilibrio" (Martínez 2013:61). Tales notas se manifiestan en el siguiente fragmento en el que, con una fuerte presencia del componente didáctico del discurso, la mandataria explica que: "Un Presidente no representa solamente eso. Un Presidente también representa un modelo de país y políticas de un país" (Fernández 2015a).

Las características antes señaladas entran en consonancia con un particular modelo de llegada sostenido por el kirchnerismo. Mientras el discurso peronista presentaba a Juan Perón como "alguien que viene de afuera" (Sigal y Verón 2003:32), destacando la exterioridad y el carácter ajeno del mismo en referencia a la arena política, el kirchnerismo no presenta en su modelo tal efecto de exterioridad en relación a la política.

La construcción del enunciador como sujeto ajeno a la disputa política representa un dispositivo dominante en el que la política es semantizada peyorativamente y que, según afirma Martínez (2013) operó en la historia argentina tanto mediante el "imaginario del cuartel" en el caso de los gobiernos militares; como el "imaginario de mercado", durante el menemismo. La discursividad kirchnerista, estructurada en torno a un modelo de llegada "desde adentro" de la política, instituida desde las figuras del militante o el estadista, representó un quiebre en este sentido (Martínez 2013).

Mariano Dagatti (2013) indica que la matriz discursiva del primer kirchnerismo se configuró a partir de un modelo de llegada que presentó un efecto de exterioridad, aunque no respecto a la posición del enunciador en referencia a la política, sino en razón de la situación de crisis en la que se encontraba sumido el país al inicio del gobierno de Néstor Kirchner. Desde esta perspectiva, sostiene el autor que este modelo que presentaba a Néstor Kirchner como alguien que venía "desde el Sur del mundo", recupera algunas de las dicotomías que estructuraron el pensamiento político en el país y presenta al sur como el espacio geopolítico de la postergación.

Así, la referencia al sur implica una semántica de la pureza y de la incontaminación; instituyéndose a este modelo de llegada "... 
como el anverso de las postergaciones nacionales y la asunción kirchnerista cobra la fuerza de una postergación por fin acabada..." (Dagatti 2013:86).

En consonancia con la discursividad adversativa característica del kirchnerismo, con la proyección de una ethos militante y su adscripción a una fuerza política nacional-popular, el modelo de llegada de los discursos de Cristina Fernández analizados presentan a la enunciadora como alguien que "viene de adentro" de la política.

En la configuración de dicho modelo, resultan fundamentales la presencia fuerte de un léxico eminentemente político, presente en la referencia constante por parte de la enunciadora a "nuestra fuerza política" (Fernández 2015a). Asimismo, la biografía de la Presidenta contribuye a la construcción de una imagen de alguien que, lejos de pretender un efecto de exterioridad en relación a la política, reivindica el debate y la confrontación como notas distintivas de la política y se asume como parte de la misma.

De esta manera, la enunciadora reconstruye su propia trayectoria al afirmar "...yo que he sido legisladora durante tanto tiempo...", a la vez que propone:

Sé que muchas veces la confrontación, la discusión, el debate no le gusta a todos y piensan que se pueden obtener las cosas sin debatir y sin confrontar. Argentinos, no nos asustemos del debate y la confrontación en tanto y en cuanto podamos hacerlo civilizada y democráticamente (...) yo quiero un país de discusión y de debate y quiero también un país de reflexión. (Fernández 2015a)

\section{CONCLUSIONES}

En las páginas anteriores analizamos, a partir de las categorías conceptuales proporcionadas por el modelo teórico de Eliseo Verón, los discursos pronunciados por la entonces Presidenta de la Nación Argentina, Cristina Fernández, durante las semanas previas a la realización del ballotaje y en los días que precedieron a la finalización del mandato presidencial.

El contexto de análisis presenta una doble singularidad puesto que se conjugaron la realización del primer ballotaje en el país, desde la reforma constitucional de 1994, con la proximidad del fin de mandato presidencial y de la asunción por parte de una fuerza opositora a la Presidencial del país. En este marco, indagamos en las características que presentaron los discursos de Cristina Fernández.

Postulamos que es posible encontrar una discursividad que opera en dos dimensiones o registros, por un lado, desde el modelo de la patria se recuperan las parejas axiológicas que delimitan las fronteras identitarias en función a nosotros/ellos, a la vez que se exhorta, desde operaciones enmarcadas en los componentes prescriptivos del discurso, al prodestinatario en su lugar de militante a cumplir con las "responsabilidades" y "obligaciones" para con la patria.

Esta discursividad, asimismo, al constituir a la propia identidad en el marco de la dicotomía fundante "patria o corporaciones", enfatiza la dimensión adversativa que caracteriza al discurso kirchnerista y cristaliza en una fuerte presencia del "otro negativo" en tales discursos. El adversario político no se agota en una caracterización determinada de la Alianza Cambiemos, sino que vincula a dicha fuerza con las corporaciones que operan como verdaderos "poderes fácticos" y representan la "antipatria".

Un segundo registro en el que operan los 
discursos analizados es aquel relacionado al paradigma discursivo de los derechos. La referencia a las principales políticas de los gobiernos kirchneristas en estos discursos cumple dos funciones: la primera, de reconstrucción y constatación de las principales medidas tomadas por los gobiernos kirchneristas y, la segunda, de inscripción de tales políticas en la lengua de los derechos. El empleo de este paradigma, que interpela al ciudadano y al individuo en tanto sujeto de derechos, se manifiesta en la presencia de entidades (tales como los trabajadores, los científicos, los jubilados) en los discursos analizados.

A su vez, a partir de operaciones inscriptas en el componente didáctico del discurso y actuando, también, en el orden de la persuasión, la enunciadora formula un conjunto de advertencias al paradestinatario a la vez que instituye al ciudadano en guardián de los derechos obtenidos.

Es entonces el ciudadano, quién debe asumir la responsabilidad de actuar si encuentra cercenados sus derechos. El presupuesto de dicha acción política es uno de los saldos que deja la experiencia kirchnerista: el "empoderamiento ciudadano" (Fernández 2015c).

En los discursos analizados encontramos, a su vez, la proyección de un ethos que se articula en torno a dos posiciones de sujeto: la trayectoria militante y la adscripción, por parte de quién enuncia, al género femenino. Inscribiéndose dentro de la genealogía y las construcciones políticas de las mujeres del peronismo, la Presidenta se proyecta como parte de la historia del movimiento y como un nuevo capítulo del mismo, a la vez que, desde su posición de mujer, destaca las desigualdades de género que redundan en mayores dificultades para la participación de las mujeres en política.

Esta discursividad fuertemente adversativa, reivindica a la política como conflicto y la democracia como litigio, celebrando el debate y la confrontación. Desde esta matriz discursiva, el modelo de llegada de Cristina Fernández, lejos de pretender un efecto de exterioridad en relación a la política, inscribe a la enunciadora como alguien que cuenta con una extensa trayectoria política, que viene "desde adentro" del campo político, lo que es enfatizado y destacado como elemento positivo en la discursividad de la Presidenta.

\section{REFERENCIAS BIBLIOGRÁFICAS}

Arfuch, L. (1987). El juego de la política. Análisis de la campaña de Luder/Alfonsín. En E. Verón (coord.). El discurso político. Lenguajes y acontecimientos. Buenos Aires, Argentina: Hachette.

Balsa, J. (comp.) (2013). Discurso, política y acumulación en el kirchnerismo. Quilmes, Argentina: Editorial de la Universidad Nacional de Quilmes.

Bonetto, S. Escenarios democráticos alternativos en la Argentina postneoliberal. En J. Aragón (Coord. principal), VIII Congreso Latinoamericano de Ciencia Política, organizado por la Asociación Latinoamericana de Ciencia Politica (ALACIP). Pontificia Universidad Católica del Perú: Perú.

Dagatti, M. (2013). Contribuciones para una cartografía discursiva del primer kirchnerismo. En J. Balsa (comp.) Discurso, politica y acumulación en el kirchnerismo. Quilmes, Argentina: Editorial de la Universidad Nacional de Quilmes.

Fernández, C. (2015a). No defiendan un gobierno, defiendan sus derechos. Unidad Ciudadana. Buenos Aires, Argentina. 29 de octubre de 2015.

Fernández, C. (2015b). Inauguración de la nueva sede de la Secretaría de Derechos Humanos. Unidad Ciudadana. Buenos Aires, Argentina. 2 de diciembre de 2015.

Fernández, C. (2015c). Palabras al pueblo argentino de la Presidenta de la Nación en Plaza de Mayo. Unidad Ciudadana. Buenos Aires, Argentina. 9 de diciembre de 2015.

Martínez, F. (s.f.). "Modelo de llegada", tópicos y límites del 
discurso kirchnerista. Recuperado de aledar.fl.unc. edu.ar/files/Martinez-Fabiana1.pdf

Martínez, F. (2010). Crisis de hegemonía y resignificación de la democracia: discursos mediáticos durante el conflicto de las entidades rurales (2008) y la discusión de la ley de medios (2009). En Red Nacional de Investigadores en Comunicación (Editor Responsable), XIV Jornadas Nacionales de Investigadores en Comunicación. Universidad $\mathrm{Na}$ cional de Quilmes, Argentina.

Martínez, F. (2013). Aproximación a algunos tópicos del "discurso kirchnerista". En J. Balsa (comp.) Discurso, politica y acumulación en el kirchnerismo. Quilmes, Argentina: Editorial de la Universidad Nacional de Quilmes.

Martínez, F. (2015). La dimensión adversativa en el discurso de los jóvenes que militan. En J. Aragón (Coord. principal), VIII Congreso Latinoamericano de Ciencia Politica, organizado por la Asociación Latinoamericana de Ciencia Politica (ALACIP). Pontificia Universidad Católica del Perú, Perú.

Montero, S. (2012). Y al final un día volvimos! Los usos de la memoria en el discurso kirchnerista (2003-2007). Buenos Aires, Argentina: Prometeo.

Mouffe, C. (1999). El retorno de lo político. Comunidad, ciudadania, pluralismo, democracia radical. Barcelona, España: Paidós.

Mouffe, C. (2000). La paradoja democrática. El peligro del consenso en la política contemporánea. Barcelona, España: Gedisa.

Retamozo, M. (2015). Prólogo. En M. Schuttenberg (autor). Las identidades nacional-populares. De la resistencia noventista a los años kirchneristas. Villa María, Argentina: Eduvim.

Sigal, S. \& Verón, E. (2003). Perón o Muerte. Los fundamentos discursivos del fenómeno peronista. Buenos Aires, Argentina: Eudeba.

Verón, E. (1980). La semiosis social. En T. Monforte (ed.). El discurso político. México D.F., México: UNAM.

Verón, E. (1987). La palabra adversativa. En E. Verón (coord.). El discurso político. Lenguajes y acontecimientos. Buenos Aires, Argentina: Hachette.

Vitale, M. (2013). Ethos y legitimación política en los discursos de asunción de la presidente argentina Cristina Fernández de Kirchner. Icono, 11 (1), 5-25.

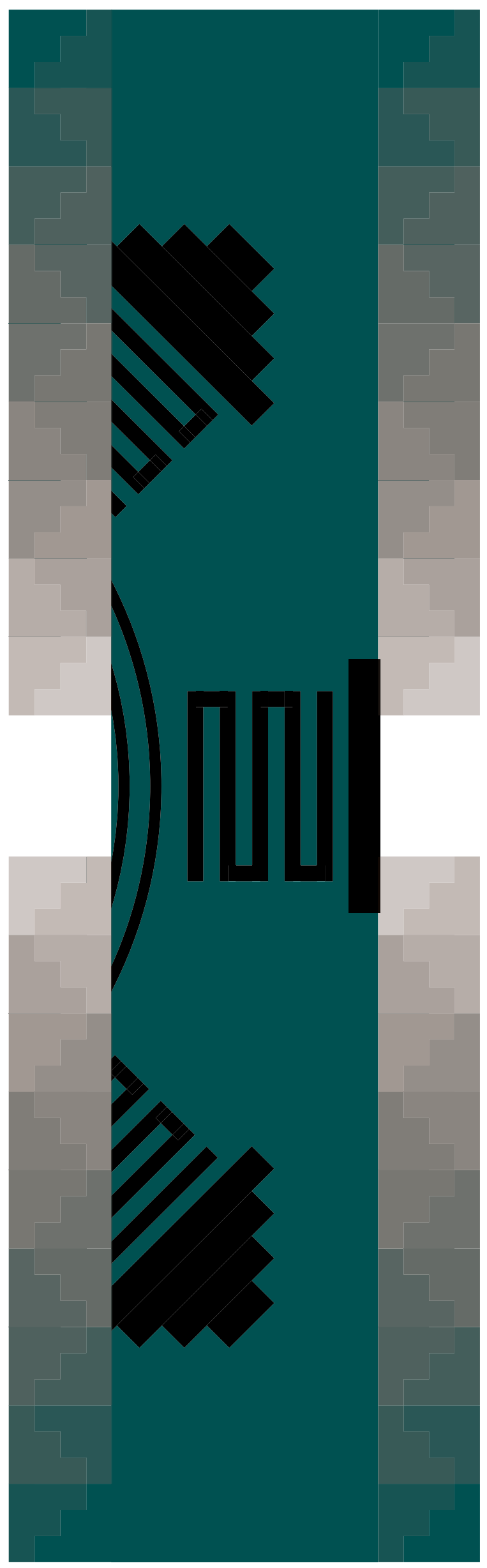

